\title{
EUROSON 2015, Athen
}

\section{EUROSON SCHOOL "Elastography \& Interventional Ultrasound" $\nabla$}

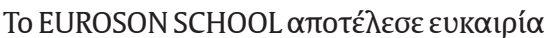

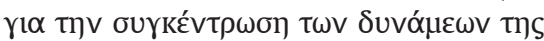

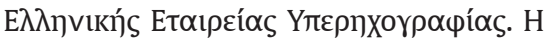

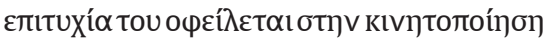

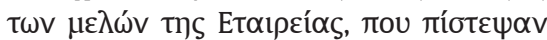

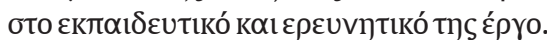

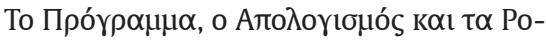

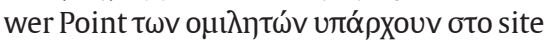

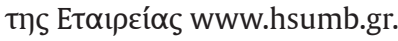

\section{EUROSON 2015, Athens, 6-8 November 2015}

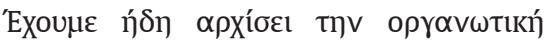

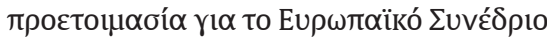

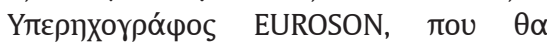

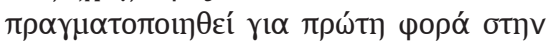

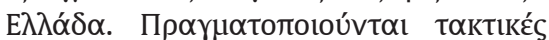

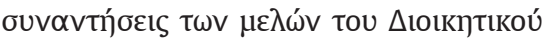

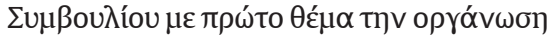

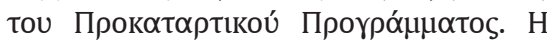

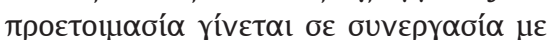

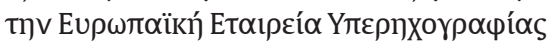

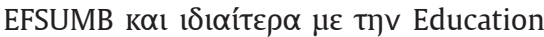

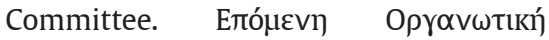

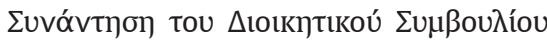

$\mu \varepsilon$ to Executive Board ths EFSUMB $\theta \alpha$

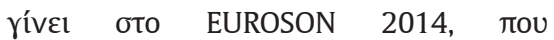

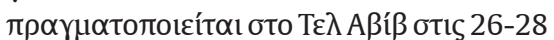
Mó́ıv 2014.

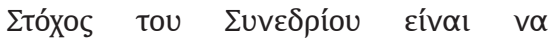

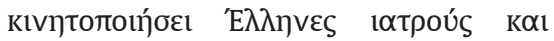

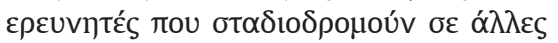

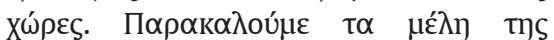

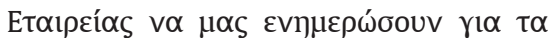

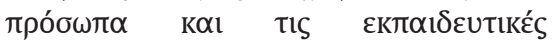

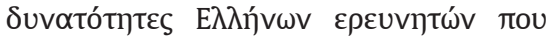

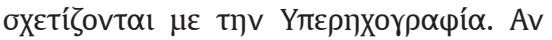

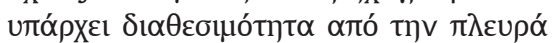

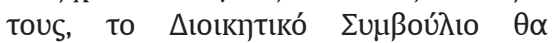

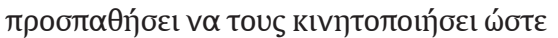

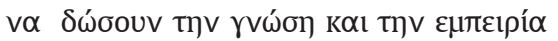

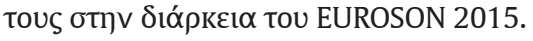

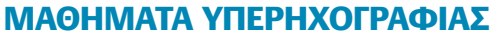
$\nabla$

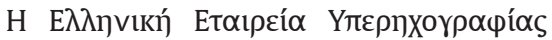

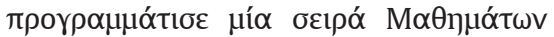

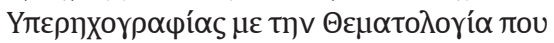

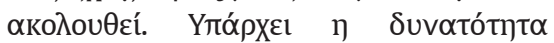

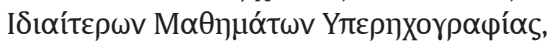

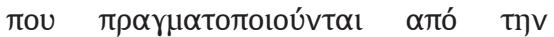

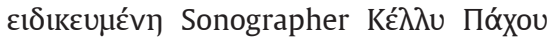

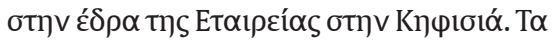

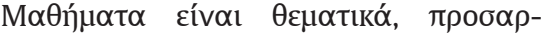

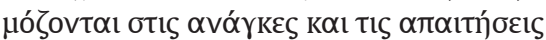

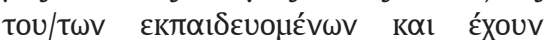

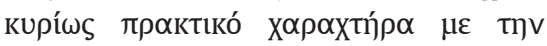

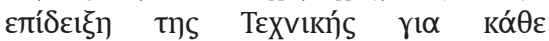

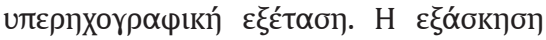

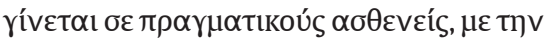

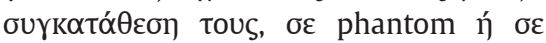

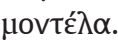

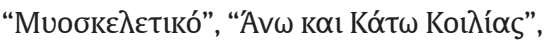

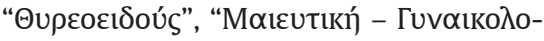

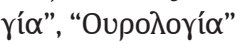

\section{EUROSON SCHOOL “Interventional | Elastography“, Istanbul Turkey, 14th-15th February 2015 $\nabla$}

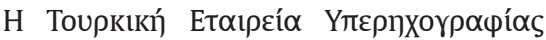

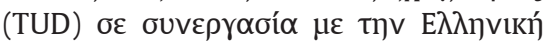

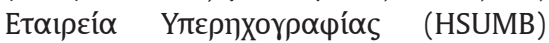
oprovóvel EUROSON SCHOOL oTnV

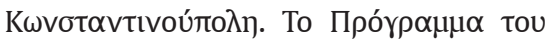
EUROSON SCHOOL vTápXEเ oTo site www. tud.org.tr.

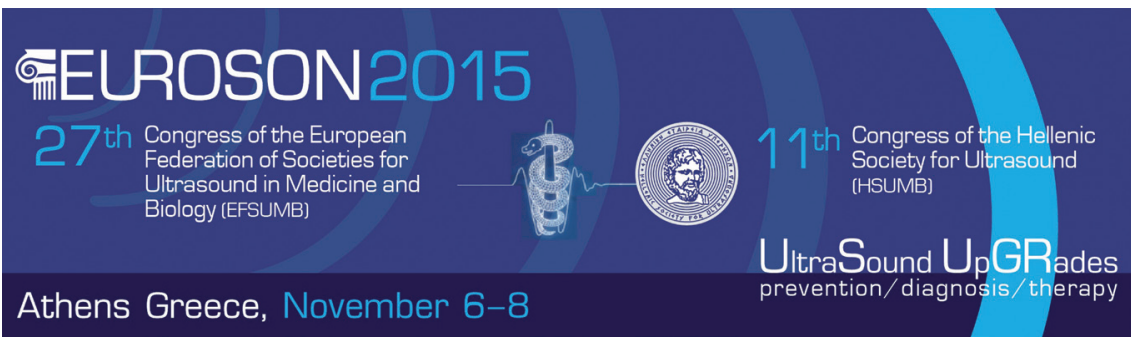

